\title{
Genetic diversity of rice stem borer (Chilo suppressalis Walker) from Northern Iran and comparison with other countries
}

\author{
M. Shayanmehr, ${ }^{1,2} \mathrm{E}$. Yoosefi-Lafooraki \\ ${ }^{1}$ Genetic and Agricultural Biotechnology Institute of Tabarestan, Sari Agricultural Sciences and \\ Natural Resources University; ${ }^{2}$ Department of Plant Protection, Sari Agricultural Sciences and \\ Natural Resources University, Sari, Mazandaran, Iran
}

\begin{abstract}
Rice striped stem borer, Chilo suppressalis Walker (Lepidoptera: Crambidae) is considered the major pest of rice in Iran. Because of the serious damage on rice in Northern Iran, the present study was conducted to investigate genetic diversity within populations of $C$. suppressalis, from Mazandaran using a template of cytochrome oxidase I gene, $750 \mathrm{bps}$, (COI). Later the haplotypes from Iran were compared with those found in other countries. According to the results of this study, there is very low genetic diversity (two haplotypes) among different populations of this pest in populations of Northern Iran. The genetic similarity and low levels of genetic diversity of these populations suggest that the pest colonization occurred relatively recently and there is high gene flow between these populations of the province. In addition, haplotypes of Mazandaran province are different with
\end{abstract}

Correspondence: Masoumeh Shayanmehr, Genetic and Agricultural Biotechnology Institute of Tabarestan (GABIT), Sari Agricultural Sciences and Natural Resources University and Department of Plant Protection, Sari Agricultural Sciences and Natural Resources University, Sari, Mazandaran, Iran. Po. Box. 578. Telefax: 011-32687567.

E-mail: Shayanm30@yahoo.com

Key words: Genetic diversity; Chilo suppressalis; cytochrome oxidase I (COI).

Acknowledgements: we would like to thank Genetic and Agricultural Biotechnology Institute of Tabarestan (GABIT), Sari Agricultural Sciences and Natural Resources University for providing financial support for this project by grant number of $\mathrm{p} / 91 / 274$. Also, we would thank to the Sari Agricultural Sciences and Natural Resources University for using technical instruments and laboratory. Also we are appreciated to Mohammad Raissi Ardali for kind help during the work.

Received for publication: 29 August 2015

Revision received: 16 July 2016.

Accepted for publication: 16 July 2016.

(C) Copyright M. Shayanmehr and E. Yoosefi-Lafooraki, 2016

Licensee PAGEPress, Italy

Journal of Entomological and Acarological Research 2016; $48: 5507$

doi:10.4081/jear.2016.5507

This article is distributed under the terms of the Creative Commons Attribution Noncommercial License (by-nc 4.0) which permits any noncommercial use, distribution, and reproduction in any medium, provided the original author(s) and source are credited. those found in other countries. The similarity of Iranian population (Simorgh) with one population from China indicated that China might be the origin of $C$. suppresalis.

\section{Introduction}

Rice is one of the world's most important crops, providing a staple food for nearly half of the global population. It is subject to attack from a range of insect pests that can significantly reduce yields (Arbab 2014). The striped stem borer, Chilo suppressalis Walker, (Lepidoptera: Crambidae) is a key pest of rice, which spread from Asia and Pacific to Middle East and Europe (Khan et al., 1991). The pole productions of rice in Iran are Mazandaran and Guilan provinces (the Northern Iran). The stem borer is the major pest of rice in Iran especially in Northern Iran. The adults are brownish yellow with silvery scales and a row of 7 or 8 small black dots at the terminal margin of each forewing. The forewings are darker than the hind wings. Damage is created by larval stages. The larvae have a large, shiny brown or orange head, the body color is light brown or pink with five rows of longitudinal stripes that run along the entire length of the body. The larvae cause dead-hearts and whiteheads.

The striped stem borer $C$. suppressalis was collected for the first time from Tonekabon and Ramsar in Mazandaran province. The pest was introduced to Iran in 1973 and then has been widely distributed in all rice fields of Iran (Zibaee et al., 2008). There is not detailed information about its settling, however it is supposed that the pest was introduced with straws surrounding citrus entered from Pakistan into the Iran (Okhovat \& Vakili, 1997). The pest was limited to Northern Iran for a while but it spread to rice fields of other parts of Iran. Moghaddas and Saiiad-nasiri (1995) reported heavy damages of the pest from other provinces such as Khuzestan, Shiraz, Isfahan and Ilam.

The rice is a main food in Asian people diet, the rice stem borer is a key pest and annually its control costs a lot for the farmers. For these reasons, several research projects have focused on different aspects of the pest as well as the genetic diversity of the stem borer populations in Asia (Ishiguro \& Tsuchida, 2006). The $C$. suppressalis has relatively limited dispersal capacity and the adults cannot disperse more than 1$3 \mathrm{~km}$ (Khan et al. 1991). The pest has discontinuous distributions. Therefore, habitat fragmentation can increase the effect of random genetic drift and lead to local adaptations and population differentiation (Avise 2000). Due to the wide distribution range and low dispersal capacity of this pest, it is expected that some genetic differentiation may occur among different local populations (Liu et al. 2013). Different kinds of genetic markers have been used for analysis of diversity in the stem borer populations (Farahpour Haghani et al., 
2014). Ishiguro and Tsuchida (2006) investigated the polymorphic microsatellite loci for the rice stem borer. The genetic diversity of $C$. suppressalis, was investigated among 18 Chinese populations by microsatellite, COI, COII, 16S and ND1 (Meng et al., 2008). High genetic diversity was found among these populations, this was expected considering the large area of the country and climate variation. Liu et al. (2013) also investigated the genetic diversity among seven populations of the stem borer in south of China by six microsatellite, $\mathrm{COI}$ and $\mathrm{COII}$ genes. The microsatellite showed polymorphism among the studied populations while the results of two mitochondrial genes indicated no significant difference between these populations and other Chinese populations.

Despite the several research work done on stem borer genetic diversity in other countries such as China, very limited information is available on the genetic variability of stem borer populations in Iran. The only noteworthy research is Farahpour Haghani et al. (2014) who investigated the genetic diversity of stem borer among populations from the Guilan province and west of Mazandaran province by RAPD marker. The results of the study indicated that populations from west, east and center of Guilan were different. Also, the populations of Guilan were different from those one of Mazandaran province.

The mitochondrial DNA proved to be very useful, given its haploid nature and maternal inheritance as well as its lack of recombination (Hewitt 2004). This gene was used frequently in genetic analysis of other insects (Chahartaghi-Abnieh 2007; Rajabiyan et al., 2015). In present study, the sequences of mtDNAs including the $\mathrm{COI}$ gene were used for characterization of genetic diversity in stem borer populations in different areas of Mazandaran province (Northern Iran). Furthermore, the sequences of mitochondrial DNA from other countries, recorded in National Center for Biotechnology Information (NCBI) were employed for comparisons.

\section{Material and methods}

Larvae of stem borer, Chilo suppressalis, were collected from different areas of Mazandaran province in Northern Iran (Table 1). The overwintering larvae were collected after rice harvesting from the infested remained stems in the farms. All samples were preserved in $70 \%$ ethanol.

Total genomic DNA was extracted from one individual specimen per each population using the CTAB protocols with some modifications (Nishiguchi et al., 2002). DNA was extracted by using a terminal part of individual larva.

The tissues were suspended in pre-warmed $\left(65^{\circ} \mathrm{C}\right)$ CTAB extraction buffer $(500 \mu \mathrm{L})$ plus -mercaptoethanol $(2 \mu \mathrm{L})$ and incubated at $65^{\circ} \mathrm{C}$ for

Table 1. Information on sampling sites in Mazandaran province.

\begin{tabular}{lccc}
$\begin{array}{l}\text { Sampling site } \\
\text { Locality }\end{array}$ & \multicolumn{2}{c}{$\begin{array}{c}\text { Coordinate } \\
\text { Longitude (N) }\end{array}$} & $\begin{array}{c}\text { Height } \\
\text { Sea above level } \\
\text { (s.a.l) (m) }\end{array}$ \\
Amol & $36^{\circ} 28^{\prime}$ & $52^{\circ} 21^{\prime}$ & 76 \\
Fereydon-Kenar & $34^{\circ} 41^{\prime}$ & $52^{\circ} 31^{\prime}$ & -21 \\
\hline Simorgh (Kiakola) & $36^{\circ} 34^{\prime}$ & $54^{\circ} 49^{\prime}$ & -7 \\
Jouybar & $36^{\circ} 33^{\prime}$ & $54^{\circ} 47^{\prime}$ & -23 \\
\hline Alasht (Savadkooh) & $36^{\circ} 07^{\prime}$ & $52^{\circ} 50^{\prime}$ & 1452 \\
Babol & $36^{\circ} 31^{\prime}$ & $52^{\circ} 35^{\prime}$ & -9 \\
\hline Noshahr & $36^{\circ} 37^{\prime}$ & $51^{\circ} 27^{\prime}$ & 452 \\
Neka & $36^{\circ} 40^{\prime}$ & $53^{\circ} 17^{\prime}$ & 31 \\
\hline
\end{tabular}

$1 \mathrm{~h}$ and a half. After that $200 \mu \mathrm{L}$ of chloroform/isoamylalcohol (24:1) solution was added and mixed for 2 min by inverting the microtube. The tubes were placed in centrifuge and the materials were spun $10 \mathrm{~min}$ at $13,000 \mathrm{rpm}$. Then the above phase was transferred to a clean microtube and cold isopropanol (in the same volume) was added. The materials were left for about $24 \mathrm{~h}$ to overnight at $20^{\circ} \mathrm{C}$ and then were spun $10 \mathrm{~min}$ at $13,000 \mathrm{rpm}$. The supernatant was removed carefully and the pellet was washed once or twice with $70 \%$ ethanol. $200 \mu \mathrm{L}$ of ethanol was added and spun at 13,000 for $10 \mathrm{~min}$. The supernatant was removed and the pellet was dried by leaving tubes open under laminar flow hood. The pellet was resuspended in sterile $\mathrm{H}_{2} \mathrm{O}$ and stored at $20^{\circ} \mathrm{C}$.

The extracted DNA from specimens was amplified using a pair primer, LC01490 (5 -GGTCAACAAATCATAAAGATATTGG-3') as forward and HC02198 HC02198 (5 -TAAACTTCAGGGTGACCAAAAAATCA-3') as reverse (Folmer et al., 1994). The COI primer pairs amplify a 750 bps fragment of the Cytochrome 0xidase subunit I gene. Amplifications were performed in $25 \mu \mathrm{L}$ microtubes containing $0.8 \mu \mathrm{L}$ $\mathrm{MgCl}_{2}, 1 \mu \mathrm{L}$ primers $(10 \mathrm{pm} / \mu \mathrm{L}), 0.5 \mu \mathrm{L}$ dNTPs, $2.5 \mu \mathrm{L}$ PCR buffer, 0.13 Taq Polymerase, $18.57 \mu \mathrm{L} \mathrm{ddH_{2 }} \mathrm{O}$, and $1.5 \mu \mathrm{L}$ DNA. The amplification program has an initial denaturation step of $5 \mathrm{~min}$ at $94^{\circ} \mathrm{C}$, followed by 35 cycles of $60 \mathrm{~s}$ in $94^{\circ} \mathrm{C}, 60 \mathrm{~s}$ in $52^{\circ} \mathrm{C}, 60 \mathrm{~s}$ at $72^{\circ} \mathrm{C}$, and a final extension of $5 \mathrm{~min}$ at $72{ }^{\circ} \mathrm{C}$. Amplification products $(5 \mu \mathrm{L})$ were visualized after electrophoresis in $2 \%$ agarose gels in TAE buffer (24.2 gr Tris, Acetic acid $71 \mathrm{~mL}$, EDTA $10 \mathrm{~mL}$ and ddH20 $60 \mathrm{~mL}$ ) with the 1-log ladder as a molecular weight marker. Purification and sequencing of PCR products for forward primer from individual specimens performed by Takapouzist Company. The accession numbers in GenBank for COI sequences of C. capitata obtained here are KT955018KT955025.

A Blast search of GenBank sequences using the sequence obtained from the PCR product was conducted through the NCBI website (http://www.ncbi.nlm.gov). Sequences were edited before analysis by BioEdit software (Hall, 2010) and then aligned using Clustal X with defaults parameters (Thompson et al., 1997). Phylogenetic trees were constructed using the Maximum Likelihood algorithm in MEGA5 (Tamura et al., 2011).

\section{Results}

Intraspecific genetic variation was investigated using molecular marker obtained from COI sequences in eight populations of the striped stem borer, $C$. suppressalis from Northern Iran. The total lengths of COI products were $750 \mathrm{bps}$. The average frequency of bases for COI marker was $\mathrm{A}=30.1 \%, \mathrm{~T}=39.06 \%, \mathrm{C}=15.97 \%$ and $\mathrm{G}=14.87 \%$. The A-T rich sequences were observed in nucleotide composition, which is a pattern that has been repeatedly seen in the mtDNA of insect species (Bajpai \& Tewari, 2010).

Phylogenetic trees were constructed using Neighbor Joining method (from 1000 bootstrap replicates) algorithms in MEGA 5 (Tamura et al., 2011). A set of striped stem borer mitochondrial DNA sequences including eighteen, available on Genbank, was used in order to compare the Iranian populations with striped stem borer populations from other geographical regions (Figure 1). The species, Ostrinia nubilalis (Hübner, 1796) (Lepidoptera: Crambidae) was used as an out-group for construction of phylogenetic trees.

The phylogenetic tree (Figure 1) shows that different populations of the stem borer are similar in COI gene sequences, being placed in one branch separated from the out-group. The population from Simorgh (Kiakola) appears to be a little bit different from the others. The phylogenetic tree also emphasizes a very close genetic similarity among populations of stem borer in Northern Iran, whereas populations of other countries show no similarity with the population in Northern Iran. 
Only, the population from Simorgh (Kiakola), shows similarity with one haplotype from China (Figure 1).

Genetic distances were calculated among the eight Iranian populations and some foreign populations using the binary data obtained from primer (Table 2). The genetic distances between northern Iranian populations were 0-0.028. The populations including Amol, Babol, Fereydonkenar, Neka, Savadkooh, Noshahr and Jouybar showed 0 genetic distance and they comprised one haplotype. Very low genetic distance values were found, indicating a high genetic similarity among the derived populations in general. The genetic distance value 0.028 is observed between Simorgh (Kiakola) and other Iranian populations, so this population is the second haplotype. The genetic distance between the Iranian populations and other countries varied from 0.235 to 0.288 .

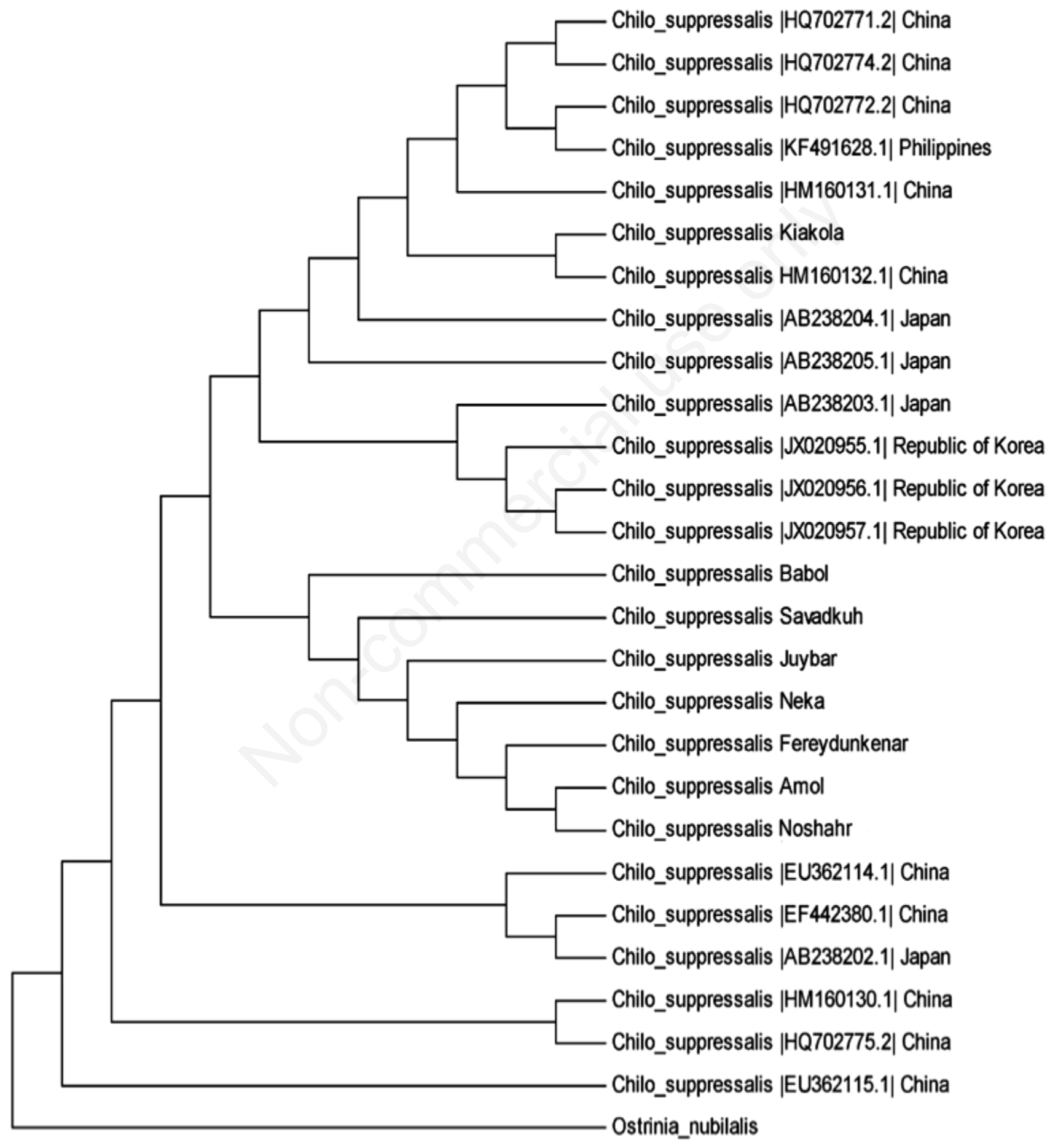

Figure 1. The phylogenetic tree of eight specimens of striped stem borer, Chilo suppressalis from Mazandaran province and eighteen other countries for COI, calculated in MEGA5. Ostrinia nubilalis used as outgroup. 


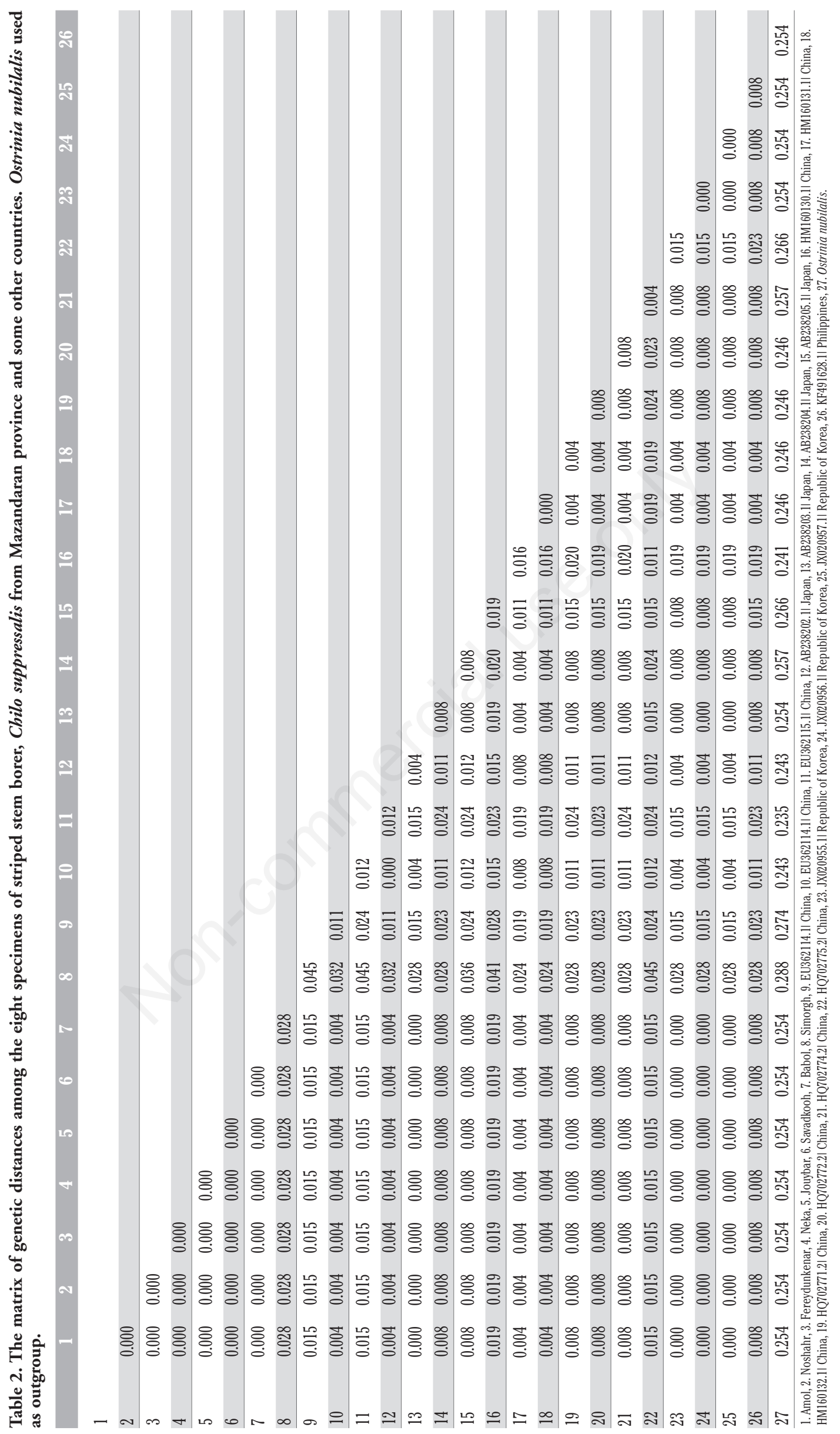




\section{Discussion}

The rice striped stem borer, Chilo suppressalis Walker, (Lepidoptera: Crambidae) is a key pest of rice in Mazandaran province as a pole of rice production in Iran. Different DNA markers, such as microsatellite, nuclear genes, RAPDs and those derived from mitochondrial DNA, have been used in other infested countries such as China, Japan and South Korea to study genetic variation in striped stem borer populations (Ishiguro \& Tsuchida, 2006; Meng, et al., 2008; Liu et al., 2013). However no research was previously carried out about genetic diversity and relationships of different populations of this pest in Iran, with the exception of the study of genetic diversity of stem borer among populations from the Guilan and west Mazandaran province by RAPD markers (Farahpour Haghani et al., 2014). Their results indicated the populations from Guilan were different from those of Mazandaran province.

The genetic distance (Nei, 1972) ranges in local races of a species; low genetic distances among populations of different areas show genetically close relationships among them (Menezes, 1990). The genetic similarities between populations of different areas could help farmers in employing the same successful control methods, since the same race pest could share the same race of natural enemy and this is a key point in for biological control. The low genetic distances found among populations of the stem borer in Mazandaran province from this study indicate that these populations are genetically similar and that colonization in the rice farms by this pest took place once and relatively recently. $C$. suppressalis was introduced to Iran in 1973 by first record from Mazandaran. The short time of pest settlement in Iran did not allow a fixing of genetic variations. The close distance between selected cities, the presence of vast rice fields between the selected sampling locations and finally, the exchanging of the rice products between the cities, caused quick distribution of stem borer in Northern Iran. Additionally, the lack of habitat fragmentation due to similarity of climate, soil composition etc. In the sampling locations have been decreased the chance of genetic divergence. Among Iranian populations, only Simorgh (Kiakola) population showed close relationship with one population from China.

The results of this study indicate that there are only two haplotypes of stem borer in Mazandaran province. Therefore, the colonization of the pest has happened more recently and the pest has not had enough time for genetic divergence. The populations from China showed older colonization than populations from other countries such as Japan, South Korea and Philippine. The populations from Mazandaran clustered separately from other countries indicating that Iranian haplotypes differ from those countries such as China. The similarity of the Iranian population Kiakola with one population from China suggests China as the origin of $C$. suppresalis. High genetic diversities of $C$. suppressalis were observed among the populations of stem borer from China (Meng et al., 2008), high diversities could be bound to long-time settlement of the pest in this country, the large extent of China, large distance between examined areas, climate variations and so on. However, the results of two mitochondrial genes ( $\mathrm{COI}$ and $\mathrm{COII}$ ) also indicated no significant genetic diversity among some Chinese populations (Liu et al., 2013). The populations from Japan, South Korea and Philippine showed close relationship to each other as well as some haplotypes from China.

Unfortunately, information of pest sequences from many of Asian countries is not available in gene bank. It could be because of high cost of DNA analysis. But, having more information on sequences analysis will provide valuable information about phylogenetic relationship between Asian countries, finding out the origin of the pest, and whether recent colonization or older colonization take place in each country. The information about sequences analysis will also allow for answering some questions relevant to pest management. For example biological control of $C$. suppressalis must consider that the same race of the pest might be share the same natural enemy.

\section{Conclusions}

The results of this study indicate no genetic diversity among $C$. suppressalis populations in Northern Iran by COI mitochondrial gene suggesting that pest colonization occurred recently. The populations from Northern Iran (Mazandaran) are separated from the ones from other infested countries such as Japan, South Korea and China. The only observed similarity of Iranian population (Kiakola) was with one population from China indicating that China might be the origin of $C$. suppresalis.

\section{References}

ARBAB A., 2014 - Spatial distribution and minimum sample size for overwintering larvae of the rice stem borer Chilo suppressalis (Walker) in paddy fields. - Neotrop. Entomol. 43: 415-420.

AVISE J.C., 2000 - Phylogeography: the history and formation of species. Harvard University Press, Cambridge, MA: 447 pp.

BAJPAI N., TEWARI R.R., 2010 - Mitochondrial DNA sequence-based phylogenetic relationship among flesh flies of the genus Sarcophaga (Sarcophagidae: Diptera). - Genetics 89: 51-54.

CHAHARTAGHI-ABNIEH M., 2007 - Trophic niche differentiation, sex ratio and phylogeography of European Collembola. - PhD thesis, Technischen University of Darmstadt, $132 \mathrm{pp}$.

FARAHPOUR HAGHANI A., HOSSEINI R., EBADI A.A., AALAMI A., 2014 Genetic variation of Chilo suppressalis Walker (Lepidoptera: Pyralidae) populations in Guilan and west of Mazandaran provinces analyzed with RAPD markers. - Plant Protect. Sci. 50: 26-35.

FOLMER O., BLACK M., HOEH W., LUTZ R., VRIJENHOEK R., 1994 DNA primer for amplification of mitochondrial cytochrome $\mathrm{c}$ oxidase subunit I from diverse metazoan invertebrate. - Mol. Mar. Biol. Biotech. 3: 294-299.

HALL T., 2010 - BioEdit. - Available from: http://www.mbio.ncsu.edu/ BioEdit/bioedit.html

HEWITT G.M., 2004 - The structure of biodiversity-insights from molecular phylogeography. - Front. Zool. 1: 1-16.

ISHIGURO N., TSUCHIDA K., 2006 - Polymorphic microsatellite loci for the rice stem borer, Chilo suppressalis (Walker) (Lepidoptera: Crambidae). - Appl. Entomol. Zool. 41: 565-568.

KHAN Z.R., LITSINGER J.A., BARRION A.T., VILLANUEVA F.F.D., FERNANDEZ N.J., TAYLO L.D. 1991 - World bibliography of rice stem borers. - IRRI, p 415.

LIU Y., HOU M., WU Y., LIU G., 2013 - Population Genetic Analysis of the Rice Stem Borer, Chilo suppressalis, in the South China. - J. Integr. Agr. 12: 1033-1041.

MENEZES M.R., 1990 - Genetic distance and phylogenetic relationship. - Biol. Educ. 7: 297-303.

MENG X.F., SHI M., CHEN X.X., 2008 - Population genetic structure of Chilo suppressalis (Walker) (Lepidoptera: Crambidae): strong subdivision in China inferred from microsatellite markers and mtDNA gene sequences. - Mol. Ecol. 17: 2880-2897.

MOGHADDAS H., NASIRI M., 1995 - Identification of rice striped stem borer in Isfahan, study of its biology and distribution. - $12^{\text {th }}$ Iranian Plant Protection Congress, Iran.

NEI M., 1972 - Genetic distances between populations. - Am. Nat. 106: 283-292.

NISHIGUCHI M.K., DOUKAKIS P., EGAN M., GOLDSTEIN P.Z., KIZIRIAN D., PHILLIPS A., PRENDINI L., ROSENBAUM H.C., TORRES E., 
WYNER Y., DESALLE R., GIRIBET G., 2002 - DNA isolation procedures. In: DESALLE R., GIRIBET G., WHEELER W.C., Techniques in Molecular Evolution and Systematics: Methods and Tools in Biosciences and Medicine. I ed. - Birkhäuser Verlag AG, Basel.: 249-287.

OKHOVAT M., VAKILI D., 1997 - Rice planting, cultivation and harvesting. - Farabi, Tehran: 212 pp.

SIMON C., FRATI F., BECKENBACH A., CRESPI B., LIU H., FLOOK P., 1994 - Evolution, weighting and phylogenetic utility of mitochondrial gene sequences and a compilation of conserved PCR primers. Ann. Entomol. Soc. Am., 87:651-701.

SOLORZANO C.D., SZALANSKI A.L., OWENS C.B., STEELMAN C.D., 2010 - Genetic diversity of Aedes vexans (Diptera, Culicidae) from New Orleans: Pre- and Post- Katrina. - Biochem. Genet. 48: 711-726.

RAJABIYAN M., SHAYANMEHR M., MOHAMMAD-SHARIF M., 2015 -
The Mediterranean fruit fly (Ceratitis capitata) in Iran: genetic diversity and comparison with other countries. - J. Entomol. Acarol. Res. 47: 20-25.

TAMURA K., PETERSON D., PETERSON N., STECHER G., NEI M., KUAR S., 2011 - MEGA5: molecular evolutionary genetics analysis using maximum likelihood, evolutionary distance and maximum parsimony methods. - Mol. Biol. Evol. 28: 2731-2739.

THOMPSON J.D., GIBSON T.J., PLEWNIAK F., JEANMOUGINN F., HIGGINS D.G., 1997 - The Clustal X windows interface: flexible strategies for multiple sequence alignment aided by quality analysis tools. - Nucleic Acids Res. 24: 4876-4882.

ZIBAEE A., SENDI J.J., ALINIA F., ETEBARI K., 2008 - A study on biochemical differences among five different groups of rice striped stem borer Chilo suppressalis Walker (Lepidoptera: Pyralidae). Invertebrate Surviv. J. 5: 20-29. 